\title{
Inter-relação entre caracteres de caupi de porte ereto e crescimento determinado ${ }^{(1)}$
}

\author{
Antônio Aécio de Carvalho Bezerra(2), Clodoaldo José da Anunciação Filho(3), \\ Francisco Rodrigues Freire Filho ${ }^{(2)}$ e Valdenir Queiroz Ribeiro ${ }^{(2)}$
}

\begin{abstract}
Resumo - Foram estudados dez caracteres em 32 genótipos de caupi [Vigna unguiculata (L.) Walp.], com o objetivo de avaliar o grau de associação existente entre o rendimento de grãos e seus componentes. O ensaio foi conduzido no Campo Experimental da Embrapa-Centro de Pesquisa Agropecuária do Meio-Norte, em Teresina, PI. Utilizou-se o delineamento experimental de blocos casualizados, com seis repetições. Os dados foram coletados nas duas fileiras centrais, subtraídas das duas primeiras covas em cada extremidade. A floração inicial e o peso de 100 grãos apresentaram, com rendimento de grãos, as maiores correlações genéticas positivas e os maiores efeitos diretos em sentido favorável à seleção, e foram os caracteres mais importantes para o processo de seleção indireta. A seleção, praticada nos caracteres ângulo de inserção dos ramos laterais e número de grãos por vagem, não teve influência direta significativa sobre o rendimento de grãos.
\end{abstract}

Termos para indexação: Vigna unguiculata, genótipos, seleção, características agronômicas, grãos, componentes de produção.

\section{Interrelation among characters of upright cowpea plants with determined growth}

\begin{abstract}
Ten characteristics were studied in 32 cowpea genotypes [Vigna unguiculata (L.) Walp.] with the objective of evaluating the association among yield and yield components. The experiment was conduced at Embrapa-Centro de Pesquisa Agropecuária do Meio-Norte in Teresina, PI, Brazil. A complete random blocks design with six replications was used. The data were collected from the two central rows subtracting two hills at the extremities. Initial flowering and 100-seed weight, that presented the highest direct effect and positive correlation with grain yield, were the most important characters in the process of indirect selection to obtain an efficient correlated response on grain yield. However, selection for the characters angle insertion of the secondary branches and number of grains per pod had no significant direct influence on grain yield.
\end{abstract}

Index terms: Vigna unguiculata, genotypes, selection, agronomic characters, grain, yield components.

\section{Introdução}

Em programas de melhoramento, o conhecimento do grau de associação entre caracteres, princi-

\footnotetext{
(1) Aceito para publicação em 3 de fevereiro de 2000.

Extraído da dissertação de mestrado apresentada pelo primeiro autor à Universidade Federal Rural de Pernambuco (UFRPE).

${ }^{(2)}$ Embrapa-Centro de Pesquisa Agropecuária do Meio-Norte (CPAMN), Caixa Postal 1, CEP 64002-220 Teresina, PI. Bolsista do CNPq. E-mail: baecio@cpamn.embrapa.br, freire@cpamn.embrapa.br, valdenir@cpamn.embrapa.br

(3)UFRPE, Dep. de Fitotecnia, Rua Dom Miguel, s/n CEP 52171-900 Recife, PE.
}

palmente quando há dificuldade de identificação e medição do caráter a ser melhorado, ou quando este tem baixa herdabilidade, pode ajudar a promover ganhos efetivos com a seleção (Cruz \& Regazzi, 1994).

As estimativas das correlações entre caracteres não permitem a quantificação das influências diretas e indiretas entre os fatores correlacionados; são apenas uma medida de associação entre caracteres, e não possibilitam conclusões sobre as relações de causa e efeito (Vencovsky \& Barriga, 1992). Desse modo, a seleção praticada em razão da correlação pode conduzir a resultados não-satisfatórios para os trabalhos de melhoramento, por não serem considerados, nas 
correlações, os efeitos de outras variáveis inter-relacionadas.

O método da "análise de trilha", desenvolvido por Wright $(1921,1923)$ e descrito detalhadamente por Li (1975), tem sido utilizado nos programas de melhoramento para quantificar a magnitude e a direção dos efeitos diretos e indiretos de cada uma das variáveis explicativas sobre a variável complexa, considerada como principal.

Oliveira (1996), empregando o método da análise de trilha, avaliou dez características em 16 genótipos de caupi, e constatou que o peso de 100 grãos e o número de vagens por planta foram as variáveis com maior efeito direto positivo sobre o rendimento de grãos.

Gopalan \& Balasubramanian (1993), estudando os componentes de produção em caupi, obtiveram, entre os caracteres altura de planta e rendimento de grãos, efeito direto inexpressivo $(0,006)$, e coeficiente de correlação genética positivo $\left(r_{G}=0,738\right)$. Segundo Vencovsky \& Barriga (1992), nesses casos, a correlação é determinada pelos efeitos indiretos, pois no processo de seleção os fatores causais indiretos devem ser considerados simultaneamente. Esse resultado demonstra a importância da análise de causa e efeito para o estudo da associação existente entre dois caracteres e da influência que outros caracteres exerçam sobre esta associação.

Com relação ao caráter floração inicial, Oseni et al. (1992) obtiveram o maior efeito direto positivo sobre o rendimento de grãos. Resultados semelhantes foram obtidos por Biradar et al. (1991) e por Siddique \& Gupta (1991, 1992).

Nos últimos anos, em virtude do interesse de médios e grandes produtores, que praticam uma agricultura mais tecnificada, tem havido um crescimento na procura por cultivares de caupi de porte ereto $\mathrm{e}$ semi-ereto e de hábito de crescimento determinado, por serem características essenciais à mecanização dos tratos culturais e da colheita. Desse modo, informações sobre genótipos portadores dessas características, principalmente referentes aos aspectos genéticos e ao grau de associação existente entre essas características e os componentes do rendimento, podem auxiliar no processo de seleção de genótipos superiores de porte ereto e semi-ereto e hábito de crescimento determinado.
O objetivo deste trabalho foi estudar o grau de associação e as relações causais entre o rendimento de grãos e seus componentes.

\section{Material e Métodos}

O ensaio foi conduzido em sistema irrigado, na área experimental da Embrapa-Centro de Pesquisa Agropecuária do Meio-Norte, em Teresina, PI, latitude de $5^{\circ} 5^{\prime} \mathrm{S}$, longitude de $42^{\circ} 48^{\prime} \mathrm{W}$ e a $72 \mathrm{~m}$ de altitude, em um solo Aluvial eutrófico moderado de textura média (Melo Filho \& Jacomine, 1980).

Foram avaliados 32 genótipos de caupi (Vigna unguiculata (L.) Walp.) precoces, de porte ereto e hábito de crescimento determinado. Utilizou-se o delineamento estatístico de blocos casualizados, com 32 tratamentos e seis repetições. Cada parcela, com uma área total de $8,0 \mathrm{~m}^{2}$, foi composta por quatro fileiras de $4,0 \mathrm{~m}$ de comprimento. $\mathrm{O}$ espaçamento entre fileiras foi de $0,50 \mathrm{~m}$, e entre plantas dentro da fileira de $0,10 \mathrm{~m}$, com 10 plantas por metro linear, correspondendo a uma densidade populacional de 200.000 plantas/ha. As duas fileiras centrais, subtraídas das duas primeiras covas em cada extremidade, compuseram a área útil da parcela, de $3,6 \mathrm{~m}^{2}$.

$\mathrm{O}$ sistema de irrigação foi previamente avaliado no campo quanto à uniformidade de aplicação d'água dos aspersores, utilizando-se a equação de Christiansen, conforme método apresentado por Bernardo (1987). O turno de rega foi determinado em razão da evapotranspiração da cultura e da disponibilidade de água no solo, irrigando-se sempre que $60 \%$ a $70 \%$ da disponibilidade real de água do solo havia sido evapotranspirada.

Os coeficientes de correlações genotípicas $\left(\mathrm{r}_{\mathrm{G}}\right)$ entre os caracteres foram estimados utilizando-se as expressões apresentadas por Vencovsky \& Barriga (1992) e Cruz \& Regazzi (1994), e desdobrados em componentes de efeito direto e indireto, pelo método da análise de trilha proposto por Wright $(1921,1923)$. De acordo com Li (1975), construiu-se um diagrama de causa-efeito mostrando as relações entre a variável básica - rendimento de grãos - e as variáveis explicativas - floração inicial, comprimento do ramo principal, número de nós no ramo principal, número de ramos laterais, ângulo de inserção dos ramos laterais, número de vagens por planta, comprimento de vagem, número de grãos por vagem e peso de 100 grãos -, como também suas inter-relações. No diagrama de causa-efeito (Figura 1), as setas unidirecionais indicam a influência direta de cada uma das variáveis explicativas sobre a variável básica, medida pelo coeficiente de trilha $P_{\mathrm{jn}}(\mathrm{j}=1,2, \ldots, 9)$, e as setas bidirecionais representam a correlação genética $\left(\mathrm{r}_{\mathrm{ij}}\right)$ entre as variáveis. 


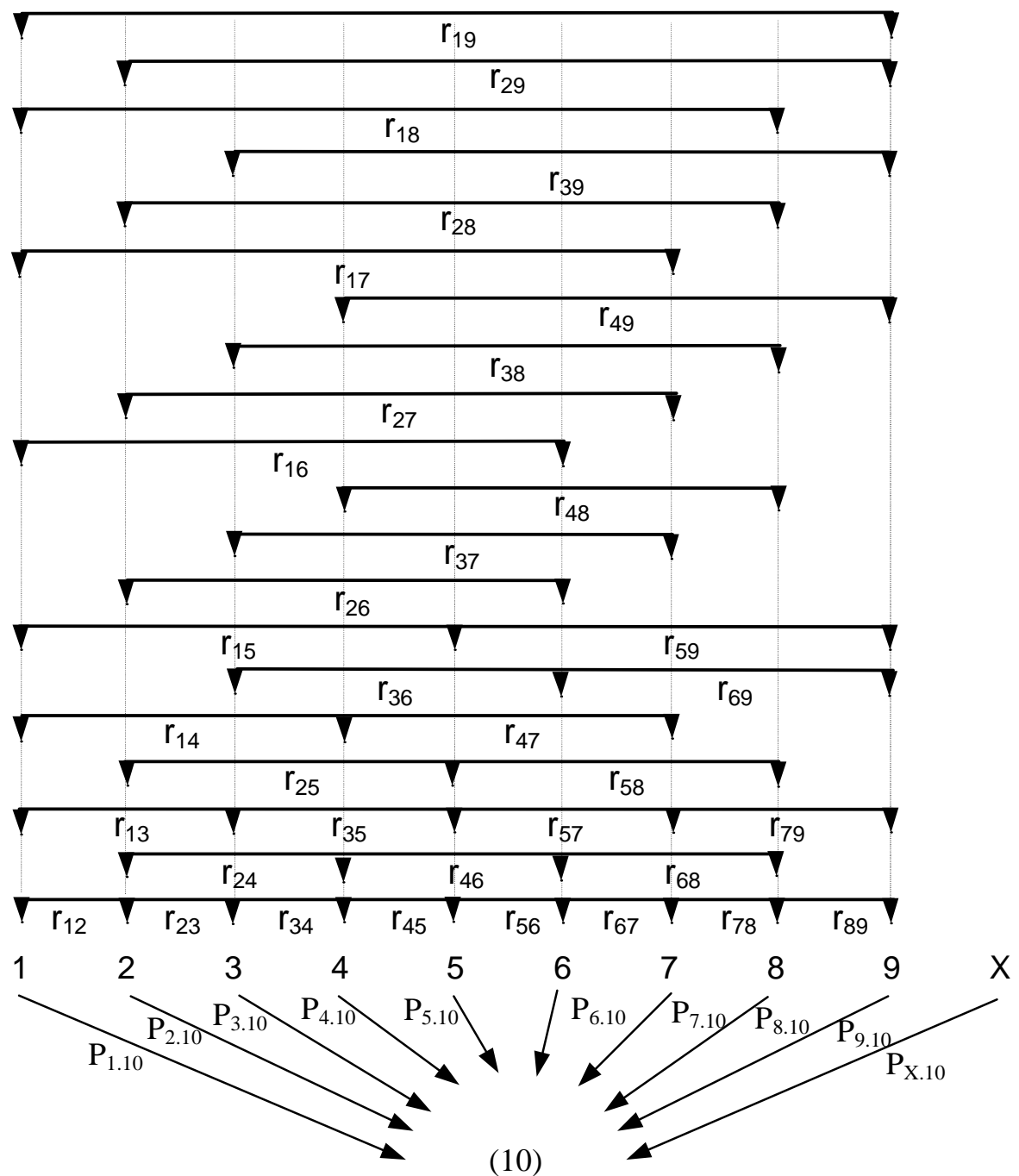

(10)

\section{1: floração inicial}

2: comprimento do ramo principal

3: no de nós no ramo principal

4: no de ramos laterais

5: ângulo de inserção dos ramos laterais

6: no de vagens por planta
7: comprimento de vagem

8: $n$ o de grãos por vagem

9: peso de 100 grãos

10: rendimento de grãos

$\mathrm{X}$ : variável residual não-correlacionada

$P$ : coeficiente de trilha

Figura 1. Diagrama do sistema de causas-efeitos, sendo as variáveis explicativas (1 a 9) correlacionadas (r) com a variável principal (rendimento de grãos) e a variável X, não-correlacionada. 
Para uma completa determinação dos efeitos, incluiuse no diagrama a variável $\mathrm{X}$ não-correlacionada, como representativa dos efeitos residuais.

Após o estabelecimento das equações básicas da análise de trilha, a resolução na forma matricial foi obtida pelo sistema de equações normais,

$\mathrm{X}^{\prime} \mathrm{X} \beta=\mathrm{X}^{\prime} \mathrm{Y}$

onde:

$\mathrm{X}^{\prime} \mathrm{X}=$ matriz não-singular das correlações entre as variáveis explicativas;

$\beta=$ vetor coluna de coeficientes de trilha;

$\mathrm{X}^{\prime} \mathrm{Y}=$ vetor coluna das correlações entre as variáveis explicativas e a variável principal.

Assim, tem-se:

$$
r_{i x}=P_{i x}+\sum_{j \neq i}^{n} r_{i j} P_{j x}
$$

onde:

$\mathrm{r}_{\mathrm{ix}}$ : correlação entre o rendimento de grãos e a i-ésima variável explicativa;

$\mathrm{P}_{\mathrm{ix}}$ : efeito direto da variável i sobre o rendimento de grãos; $\mathrm{r}_{\mathrm{ij}} \mathrm{P}_{\mathrm{jx}}$ : efeito indireto da variável $\mathrm{i}$, via a variável $\mathrm{j}$, sobre o rendimento de grãos.

A solução de mínimos quadrados desse sistema é dada por: $\beta=\left(X^{\prime} X\right)^{-1} X^{\prime} Y$.

O coeficiente de determinação $\left[\mathrm{R}^{2} 10(1,2, \ldots, 9)\right]$ do modelo causal que mede o efeito das nove variáveis explicativas sobre a variável básica rendimento de grãos é dado por:

$\mathrm{R}_{10(1,2, \ldots, 9)}^{2}=\mathrm{P}^{2}{ }_{110}+\mathrm{P}_{210}^{2}+\ldots+2 \mathrm{p}_{810} \mathrm{r}_{8.9} \mathrm{p}_{910}$,

e os efeitos residuais expressos por:

$\mathrm{P}^{2} \mathrm{X} 10=\left[1-\mathrm{R}^{2} 10(1,2, \ldots, 9)\right]^{1 / 2}$.

As análises foram realizadas pelo programa computacional Genes (Cruz, 1996).

\section{Resultados e Discussão}

O caráter rendimento de grãos apresentou correlações genéticas (Tabela 1) significativa $(\mathrm{p}<0,01) \mathrm{e}$ positiva com floração inicial $\left(\mathrm{r}_{\mathrm{G}}=0,607\right)$ e peso de 100 grãos $\left(r_{G}=0,719\right)$, e significativa e negativa com o número de ramos laterais $\left(\mathrm{r}_{\mathrm{G}}=-0,548\right)$. Resultados semelhantes foram obtidos por Apte et al. (1991) e Siddique \& Gupta (1991) em relação à floração inicial; por Singh \& Mehndiratta (1969), Teware \& Gautmam (1989) e Tamilselvam \& Vijendra (1994), com relação ao peso de 100 grãos, e por Oliveira (1996), quanto ao número de ramos laterais. Quanto aos demais caracteres, não foram detectadas

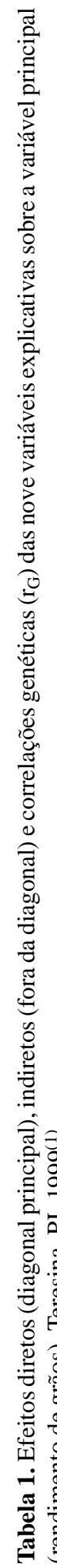


correlações genéticas significativas com rendimento de grãos.

Os maiores efeitos diretos positivos sobre o rendimento de grãos foram expressos (Tabela 1) pelos caracteres floração inicial $(0,8808)$ e peso de 100 grãos $(0,7847)$, cujos valores são semelhantes, em magnitude e sinal, aos coeficientes de correlação genética obtidos entre os referidos fatores causais e o rendimento de grãos. Essa semelhança evidencia que as correlações genéticas explicam a verdadeira associação existente entre estes caracteres. Nesses casos, a seleção direta sobre os caracteres floração inicial e/ou peso de 100 grãos teria uma resposta correlacionada eficiente sobre o rendimento de grãos, deveriam, portanto, ser considerados na seleção de parentais (Bezerra, 1997). Efeitos diretos concordantes com os do presente estudo são apresentados por Oseni et al. (1992) e Siddique \& Gupta (1992).

O coeficiente de correlação genética obtido entre floração inicial e rendimento de grãos $\left(\mathrm{r}_{\mathrm{G}}=0,6071\right)$ é explicado pelos efeitos direto $(0,8808)$ e indireto $(0,2221)$, via peso de 100 grãos, os quais foram contrabalançados principalmente pelos efeitos indiretos negativos, via número de nós no ramo principal $(-0,3200)$ e número de vagens por planta $(-0,1214)$, que reduziram o valor da correlação. Desse modo, a seleção para fins de precocidade provocará perdas no rendimento de grãos, dificultando os trabalhos de melhoramento que objetivem aumentar simultaneamente a precocidade e o rendimento de grãos.

$\mathrm{O}$ efeito direto $(0,7847)$, expresso pelo peso de 100 grãos sobre a variável principal, e combinado com os efeitos indiretos positivos via floração inicial $(0,2493)$ e via número de ramos laterais $(0,1267)$, e compensado pelos efeitos indiretos negativos via número de nós no ramo principal $(-0,1527)$, comprimento de vagem $(-0,1279)$ e número de vagens por planta $(-0,1071)$, foi responsável pela alta correlação $(0,7193)$ entre o peso de 100 grãos e o rendimento de grãos. Os dados ratificam a importância do caráter peso de 100 grãos em programas de melhoramento, por viabilizar uma resposta correlacionada eficiente por meio da seleção indireta.

Os caracteres número de nós no ramo principal e número de vagens por planta apresentaram efeitos diretos negativos $(-0,5219$ e $-0,6576$, respectivamente) e correlações genéticas positivas de média magnitude $\left(\mathrm{r}_{\mathrm{G}}=0,3226\right.$ e $\mathrm{r}_{\mathrm{G}}=0,2959$, respectivamente) com rendimento de grãos. Desse modo, os efeitos indiretos do número de nós no ramo principal via floração inicial $(0,5402)$, do peso de 100 grãos $(0,2296)$, e do número de vagens por planta via floração inicial $(0,1627)$, comprimento de vagem $(0,4605)$ e peso de 100 grãos $(0,1279)$ sobre o rendimento de grãos, justificam as referidas correlações. Tais dados indicam que os fatores causais indiretos devem ser considerados simultaneamente, durante o processo de seleção.

$\mathrm{O}$ efeito direto negativo apresentado pelo comprimento de vagem $(-0,6330)$ sobre o rendimento de grãos foi compensado pelos efeitos indiretos positivos via número de vagens por planta $(0,4784)$ e peso de 100 grãos $(0,1585)$, e explicam a ausência de correlação $\left(r_{G}=0,0609\right)$ entre esses caracteres. A seleção direta sobre o caráter comprimento de vagem terá efeito desfavorável sobre o rendimento de grãos, conforme já relatado por Jana et al. (1983) e Biradar et al. (1991).

O número de ramos laterais mostrou efeito direto negativo e de baixa magnitude $(-0,1888)$ sobre o rendimento de grãos, o qual, juntamente com o efeito indireto via peso de 100 grãos (-0,5265), é responsável pela correlação genética negativa e de média magnitude $\left(r_{G}=-0,5481\right)$ estimada entre os referidos caracteres.

Os caracteres ângulo de inserção dos ramos laterais e número de grãos por vagem apresentaram os menores efeitos diretos $(-0,0850$ e $-0,0073$, respectivamente) e correlações genéticas inexpressivas $\left(r_{G}=0,0316\right.$ e $r_{G}=-0,0166$, respectivamente) com rendimento de grãos. Esses dados indicam pouca ou nenhuma contribuição desses fatores causais na expressão do caráter rendimento de grãos (Bezerra, 1997), e portanto, não devem ser considerados no processo de seleção indireta.

O coeficiente de determinação do modelo causal, quando consideradas as nove variáveis explicativas, foi de $\mathrm{R}^{2} 10(1,2,3 \ldots, 9)=0,8432$, indicando, assim, que o modelo causal adotado explica satisfatoriamente o rendimento de grãos, mediante os efeitos diretos e indiretos das variáveis explicativas consideradas. 


\section{Conclusões}

1. A seleção indireta via floração inicial ou peso de 100 grãos possibilita resposta correlacionada eficiente no que diz respeito ao rendimento de grãos.

2. Os caracteres número de nós no ramo principal e número de vagens por planta devem ser considerados, simultaneamente, no processo de seleção.

3. A seleção praticada no que se refere ao ângulo de inserção dos ramos laterais e ao número de grãos por vagem não tem influência significativa sobre o rendimento de grãos.

\section{Referências}

APTE, U. B.; CHAVAN, S. A.; JADHAV, B. B. Correlation studies in cowpea. Agricultural Science Digest, Karnal, v. 11, n. 2, p. 59-62, 1991.

BERNARDO, S. Manual de irrigação. Viçosa : UFV, 1987. $488 \mathrm{p}$.

BEZERRA, A. A. de C. Variabilidade e diversidade genética em caupi [Vigna unguiculata $(\mathrm{L}$.) Walp.] precoce, de crescimento determinado e porte ereto e semiereto. Recife : UFRPE, 1997. 105 p. Dissertação de Mestrado.

BIRADAR, B. D.; GOUD, J. V.; PATIL, S. S. A study on character association and path coefficient in cowpea. Journal Maharashtra Agricultural Universities, Poona, v. 16 , n. 1 , p. 27-29, 1991.

CRUZ, C. D. Genes: programa para análise e processamento de dados baseado em modelo de genética e estatística experimental. Viçosa : UFV-Imprensa Universitária, 1996. $350 \mathrm{p}$.

CRUZ, C. D.; REGAZZI, A. J. Modelos biométricos aplicados ao melhoramento genético. Viçosa : UFV-Imprensa Universitária, 1994. 390 p.

GOPALAN, A.; BALASUBRAMANIAN, M. Component analysis for fodder yield in cowpea. Madras Agricultural Journal, Coimbatore, v. 80, n. 4, p. 190-193, 1993.

JANA, S.; SOM, M. G.; DAS, N. D. Correlation and path analysis of vegetable pod yield components in cowpea (Vigna unguiculata var. Sesquipedalis). Haryana Journal of Horticultural Science, Haryana, v. 12, n. 3, p. 224-227, 1983.
LI, C. C. Path analysis: a primer. Pacific Grove : Boxwood, 1975. 346 p.

MELO FILHO, H. F.; JACOMINE, P. K. T. Levantamento detalhado dos solos da área da UEPAE-TeresinaPiauí. Rio de Janeiro : Embrapa-SNLCS, 1980. 154 p. (Embrapa-SNLCS. Boletim Técnico, 69).

OLIVEIRA, F. J. de. Análises uni e multivariada aplicadas em cultivares de feijão macassar (Vigna unguiculata (L.) Walp.). Recife : UFRPE, 1996. 136 p. Tese de Doutorado.

OSENI, T. O.; LENGE, D. D.; PAL, U. R. Correlation and path-coefficient analysis of yield attributes in diverse lines of cowpea (Vigna unguiculata). Indian Journal of Agricultural Sciences, New Delhi, v. 62, n. 6, p. 365-368, 1992.

SIDDIQUE, A. K. M. A. R.; GUPTA, S. N. Path coefficient analysis of yield components in cowpea (Vigna unguiculata (L.) Walp.). Annals of Biology, Hissar, v. 8, n. 1, p. 77-80, 1992.

SIDDIQUE, A. K. M. A. R.; GUPTA, S. N. Study on the cause and effect relationship among the quantitative traits of caupi (Vigna unguiculata (L.) Walp.). International Journal of Tropical Agriculture, Hissar, v. 9, n. 2, p. 149-152, 1991.

SINGH, K. B.; MEHNDIRATTA, P. D. Genetic variability and correlation studies in cowpea. Indian Journal of Genetics and Plant Breeding, Calcutta, v. 30, n. 2, p. 104109, 1969.

TAMILSELVAM, A.; VIJENDRA, L. D. das. Correlation studies in cowpea [Vigna unguiculata (L.) Walp. ] for seed yield. Madras Agricultural Journal, Coimbatore, v. 81, n. 8, p. 445-446, 1994.

TEWARE, A. K.; GAUTMAM, N. C. Correlation and path coefficient analysis in cowpea (Vigna unguiculata (L.) Walp). Indian Journal of Horticulture, Bangalore, v. 46, n. 4, p. 516-521, 1989.

VENCOVSKY, R.; BARRIGA, P. Associação entre caracteres. In: VENCOVSKY, R.; BARRIGA, P. Genética biométrica no fitomelhoramento. Ribeirão Preto : Sociedade Brasileira de Genética, 1992. p. 335-486.

WRIGHT, S. Correlation and causation. Journal of Agricultural Research, Islamabad, v. 20, p. 557-585, 1921.

WRIGHT, S. The theory of path coefficients: a replay to Niles' criticism. Genetics, Bethesda, v. 8, p. 239-255, 1923. 